\title{
Non-natural deaths in two health districts
}

\author{
J W KEELING, J GOLDING, AND H K G R MILLIER
}

John Radcliffe Maternity Hospital, Oxford, and Department of Child Health, University of Bristol

SUMmaRY Details of all deaths in children (less than 16 years) resident in Oxfordshire and West Berkshire from 1970-9 were ascertained; 259 non-natural deaths were identified. Half were due to road traffic accidents, and another quarter occurred during play outside the home.

There were differences in sex, age, and social class between the types of accident. A clustering of fatal accidents, particularly to pedestrians, was observed at around the time of the child's birthday. It is suggested that the excitement engendered overrides the child's normal caution.

Local action to reduce accidents from specific hazards might complement national education campaigns.

\begin{abstract}
Although the death rate in children has fallen substantially over the past 50 years, there is still room for improvement. Accidents are now the major cause of death in childhood with over 1000 registered in England and Wales in $1983 .{ }^{1}$ While advances in prevention have been made, epidemiological studies into factors associated with fatal accidents may suggest possibilities for future legislation or parental education to prevent further fatalities. These may be geographically related. We describe deaths from accidents in two largely prosperous, mainly rural districts and look for locally applicable preventive measures.
\end{abstract}

\section{Material and methods}

Information for this study was obtained from the files of the Oxford Record Linkage Study. ${ }^{2}$ All death certificates of children dying up to and including 16 years of age, between 1970 and 1979, while resident in Oxfordshire and West Berkshire were identified. Those with one or more causes of death coded as 'accidents and violence' (ICD 800-999) were identified. Further information was obtained from hospital records, necropsy reports, or newspapers filed in public libraries. On the basis of the information obtained, deaths were either excluded or grouped into one of four categories listed below. Social class based on paternal occupation was coded using the Registrar General's Classification of Occupation. ${ }^{3}$

Exclusions. For 17 infants aged between 1 month and 1 year, 'accidental asphyxia' or 'asphyxia due to inhalation of vomit' was recorded on the death certificate. This was not supported by records or necropsy reports and these children are presumed to be sudden unexpected infant deaths. ${ }^{4}$ Three children aged between 1 and 4 years were certified as dying from inhalation of vomit, but again this was unconfirmed. They have been assumed to be natural deaths and omitted from further study.

Classification. The remaining deaths were classified as follows:

(1) Road traffic accident-any death due to collision with, or otherwise involving a motorised vehicle, or bicycle, or animal on the public highway.

(2) Accidents at play-deaths due to accidents outside the home, including drowning and sports activities.

(3) Domestic accidents-includes scalds, fires, fumes, inhalation of foreign bodies, falls, occurring in the home environment.

(4) Other-the remainder.

\section{Results}

Non-natural deaths were identified in a total of 259 infants and children from birth to age 16 years. This gives an overall rate of $10 \cdot 8 / 100000$ children per year. Half of the deaths were road traffic accidents, a quarter were accidents at play, and only a sixth occurred in the home.

Road traffic accidents. There were 129 fatal road traffic accidents $(5 \cdot 4 / 100000$ per year). Over half of the children (70) were pedestrians; 67 had been in collision with a motor vehicle and three with a motor cycle. Twenty nine children were cycling at the time 
of the accident, 24 had collided with a motor vehicle, and in five accidents no other vehicle was involved. Twenty nine children had been passengers in vehicles at the time of the accident, in 21 their transport collided with another vehicle, in six no other vehicle was involved. Two children were passengers in a coach that crashed in a snow storm and one fell off a bolting pony in the path of an oncoming car. Where another vehicle was involved, commercial vehicles were more frequently involved in cycle accidents (33\%) than with pedestrians $(16 \%)$.

Accidents at play. Forty four $(65 \%)$ of the 68 fatal accidents $(2 \cdot 8 / 100000$ per year) at play outside the home were the result of drowning. All were deaths in fresh water, 10 in swimming pools, three in a canal, eight in a pond, 18 in a river, and five in other water sources. The river was the commonest site for drowning fatalities and all occurred in the Thames which is wide and fast flowing in Oxfordshire and West Berkshire. Most children had fallen in from the bank, two drowned while swimming, (one when his canoe capsized) and another fell off a motor boat. Ten children drowned in swimming pools; three were family pools, three drowned in hotel pools, one in a private pool, and one climbed through a fence round a school pool at a weekend.

There were 24 other fatal accidents during play. Seven were crush injuries; in one a cricket pitch sight screen collapsed, in another a wall collapsed, three occurred to boys playing on iron gates and one on a mechanical lawn roller.

Two boys accidentally hanged themselves, one fell into a grain store and suffocated, and one suffocated inside a polythene bag. Three accidents involved fire arms; one girl shot herself, a boy was fatally injured by his brother, and one boy was shot during an organised game shoot. There were three deaths after an injury to the neck; one boy was hit by a javelin, another by a stick, and the third fell onto a rose bush. Two children were electrocuted when they touched overhead cables, and a third was struck by lightning. Two teenagers were struck by trains when straying near railway lines. Two young children fell onto hard surfaces and sustained skull fractures.

Domestic accidents. Forty children died in accidents in and around the home. Twenty two of the deaths were asphyxial in type, 11 involved domestic fires, and three involved faulty heating appliances. In four, a bedroom fire involving bedclothes was mentioned, and in three the fire was of a particularly serious nature. Two asphyxial deaths occurred from accidental suspension of infants in a bed or cot and a third died when his pushchair collapsed. Five children inhaled foreign bodies, four were three years or younger, one had Down's syndrome. The offending objects were a sweet, a marble, a grape, and a feeding bottle teat. An 11 year old inhaled a deflated balloon.

Nine deaths resulted from falls: five children fell from windows, one infant fell off a ladder, a 4 year old fell downstairs, one baby of 8 months fell off a table, and another was dropped by his mother. Three children were electrocuted in the home; a boy of $15 \mathrm{had}$ a faulty record player in the bathroom and an infant put her fingers into an electric point. Two children died after burns from boiling water; the last following laceration on a glass door.

Other. The 22 children in this group included five where inhalation of vomit complicated pre-existing disease: two had long standing brain damage affecting motor function, two had gastrointestinal infections, and one boy had asthma. Two children died in hospital; one from morphine overdose and one düring operation for hiatus hernia.

Two pairs of siblings were murdered by a parent and on three occasions manslaughter was recorded. One infant death from hypothermia was exacerbated by maternal neglect; an asphyxial death at age 2 hours followed unattended home delivery; and an open verdict was recorded after fatal skull fracture in an infant. There was one known suicide (boy 14 years), but open verdicts were recorded on two teenagers who hanged. These deaths occurred on consecutive days when capital punishment was being hotly debated and carried by the media as 'the hanging debate'.

Age and sex differences. More than twice as many boys (179) were fatally injured as girls (80) - the rates were 14.4 deaths/100 000 boys per year and 6.9/100 000 girls. Deaths to boys greatly exceeded those to girls in all groups over 1 year of age.

The sex difference was most noticeable $(5 \cdot 18: 1)$ when accidents occurred at play, and least $(1 \cdot 5: 1)$ for domestic accidents. The sex ratio varied between types of road traffic accident, being high for pedestrians $(2 \cdot 33: 1)$ and cyclists $(2 \cdot 22: 1)$ but lower for injury to passengers $(1 \cdot 23: 1)$.

The risk of non-natural death per 100000 children is highest in the preschool age group, and lowest among 15 and 16 year olds (Table 1). Age distribution varied with the type of accident: deaths to cyclists were most common in the 10 to 14 year age group, pedestrian fatalities to 5 to 9 year olds, drowning was most common in children under age 10 years, and domestic accidents commonest in the under $5 s$. 
Table 1 Age differences by cause of accident

\begin{tabular}{|c|c|c|c|c|c|}
\hline & \multicolumn{5}{|c|}{ Age (years) } \\
\hline & $<1$ & $1-4$ & $5-9$ & $10-14$ & $15-16$ \\
\hline Road traffic accidents $\dagger$ & 1 & 24 & 44 & 50 & 10 \\
\hline Pedestrian & - & (17) & (32) & (20) & (1) \\
\hline Cyclist & - & (1) & (7) & (19) & (2) \\
\hline Passenger & (1) & (6) & (5) & (11) & (6) \\
\hline Accidents at play & 0 & 23 & 26 & 14 & 5 \\
\hline Drowning & - & (19) & (17) & (6) & (2) \\
\hline Other & - & (4) & (9) & (8) & (3) \\
\hline Domestic & 7 & 26 & 4 & 2 & $i$ \\
\hline Other & 6 & 5 & 4 & 6 & 1 \\
\hline Total & 14 & 78 & 78 & 72 & 17 \\
\hline Population at risk per year & 12200 & 52300 & 73100 & 72300 & 30300 \\
\hline $\begin{array}{l}\text { Risk of non-natural death } \\
\text { per } 10000 \text { per year }\end{array}$ & $11 \cdot 5$ & 14.9 & $10 \cdot 7$ & $10 \cdot 0$ & $5 \cdot 6$ \\
\hline
\end{tabular}

†Including equestrian.

Table 2 Non-natural deaths by social class

\begin{tabular}{|c|c|c|c|c|c|}
\hline \multirow[t]{2}{*}{ Type of death } & \multicolumn{5}{|l|}{ Social class } \\
\hline & Non-manual & $I I I M$ & $I V \& V$ & Other/NS & $\begin{array}{l}\text { Manual: } \\
\text { non-manual }\end{array}$ \\
\hline Road traffic accidents $\dagger$ & 36 & 53 & 20 & 20 & 2.0 \\
\hline Pedestrian & (12) & $(33)$ & (14) & (11) & $(3 \cdot 9)$ \\
\hline Cyclist & (11) & (12) & (2) & (4) & $(1 \cdot 3)$ \\
\hline Passenger & (12) & (8) & (4) & (5) & $(1 \cdot 0)$ \\
\hline Accidents at play & 22 & 19 & 14 & 13 & 1.5 \\
\hline Drowning & (15) & (11) & (9) & (9) & $(1 \cdot 3)$ \\
\hline Other & (7) & (8) & (5) & (4) & (1.9) \\
\hline Domestic accidents & 6 & 9 & 12 & 13 & 3.5 \\
\hline Other & 5 & 5 & 3 & 9 & 1.6 \\
\hline Total non-natural deaths & 69 & 86 & 49 & 55 & $2 \cdot 0$ \\
\hline
\end{tabular}

†Including equestrian.

NS $=$ not specified.

Social class differences. Overall, there were twice as many accidental deaths to children whose fathers were in manual occupations than those where fathers were in non-manual occupations (Table 2), but there were differences between accident groups. Equal numbers of children from non-manual and manual social classes were involved in road traffic accidents to both cyclists and passengers, but among pedestrians, four times as many manual as nonmanual children were affected. Social class difference was greatest for domestic accidents; the manual:non-manual ratio was 3.5 (total population $0.92)$.

Events occurring around the time of birthday. During examination of death certificates, an excess of accidents was noted close to the child's birthday. We identified all children whose accident occurred within 7 days (before or after) of their birthday, a total of 20 were found, which is significantly more than the 9.74 expected by chance (Table 3 ). Two other non-natural deaths occurred within a week of the birthday (expected 0.9). Details of the 20

Table 3 Fatal accidents within seven days of child's birthday

\begin{tabular}{lrl}
\hline & Observed & Expected \\
\hline $\begin{array}{l}\text { Road traffic accidents } \\
\text { Pedestrian }\end{array}$ & 10 & \\
$\quad$ Cyclist & 2 & $2 \cdot 88^{*}$ \\
$\quad$ Passenger & 2 & $1 \cdot 19$ \\
Total $\dagger$ & 14 & $1 \cdot 19$ \\
Accidents at play & & $5 \cdot 30^{*}$ \\
$\quad$ Drowning & 2 & \\
$\quad$ Other & 0 & $1 \cdot 81$ \\
Total & 2 & $0 \cdot 99$ \\
$\quad$ Domestic accidents & 4 & $2 \cdot 80$ \\
Total accidents & 20 & $1 \cdot 64$ \\
\hline
\end{tabular}

†Including equestrian.

${ }^{*} \mathrm{P}<0 \cdot 001$. 
Table 4 Fatal accidents within seven days of child's birthday

\begin{tabular}{|c|c|c|c|c|c|}
\hline $\begin{array}{l}\text { Case } \\
\text { no }\end{array}$ & Age & Sex & $\begin{array}{l}\text { Social } \\
\text { class }\end{array}$ & $\begin{array}{l}\text { Relation of } \\
\text { accident to } \\
\text { birthday (days) }\end{array}$ & Type of accident \\
\hline 1 & 2 & $\mathbf{M}$ & V & +1 & Fall from window \\
\hline 2 & 4 & $\mathrm{~F}$ & IIIN & -4 & RTA: pedestrian/car \\
\hline 3 & 5 & $\mathrm{~F}$ & IIIM & +1 & RTA: pedestrian/motor van \\
\hline 4 & 5 & $\mathbf{M}$ & IIIM & +3 & RTA: pedestrian/car \\
\hline 5 & 6 & $\mathbf{M}$ & I & +1 & RTA: pedestrian/car \\
\hline 7 & 7 & $\mathbf{M}$ & NS & +2 & Drowning/open soak-away pit \\
\hline 8 & 8 & $\mathbf{F}$ & II & -6 & RTA: cycle/vehicle \\
\hline 9 & 9 & $\mathrm{~F}$ & II & -2 & Fall from window \\
\hline 10 & 10 & $\mathbf{M}$ & II & +1 & RTA: cyclist/lorry \\
\hline 11 & 10 & $\mathbf{M}$ & I & -2 & RTA: pedestrian/car \\
\hline 12 & 10 & $\mathbf{M}$ & IV & -6 & RTA: wheeling bicycle/car \\
\hline 13 & 11 & $\mathbf{M}$ & NS & +2 & Inhalation of deflated balloon \\
\hline 14 & 12 & $\mathbf{M}$ & $\mathbf{A F}$ & +4 & RTA: pedestrian/car \\
\hline 15 & 13 & $\mathbf{M}$ & IIIM & 0 & RTA: pedestrian/car \\
\hline 17 & 2 & $\mathbf{M}$ & IIIM & +6 & RTA: in pram/motor cycle \\
\hline 18 & 3 & $\mathbf{F}$ & IV & +5 & Domestic fire \\
\hline 19 & 5 & $\mathbf{F}$ & I & -2 & RTA: passenger/car/out of control \\
\hline 20 & 15 & $\mathbf{F}$ & IV & -1 & RTA: passenger/car/car \\
\hline
\end{tabular}

$\mathrm{NS}=$ not specified; $\mathrm{AF}=$ armed forces; $\mathrm{RTA}=$ road traffic accident. In cases 1-16 the child was an active participant; in cases $17-20$ the child had an entirely passive role.

accidents are shown in Table 4 ; in 16 , the child was an active participant in the accident.

The greatest difference between observed and expected deaths was among pedestrians-10 occurred in the 14 days surrounding the birthday when only 2.8 would be expected. An excess of falls from windows was also observed $(0.2$ expected, 2 observed).

\section{Discussion}

This study examined causes of non-natural deaths in a specified area of England. It is largely rural in composition with several small towns and two moderately sized cities (Oxford and Reading). There are no major slum areas and little heavy industry. Our findings are different from studies undertaken in industrial areas, ${ }^{5}$ and identify problems within Oxfordshire and West Berkshire that may be amenable to local remedies.

Deaths from drowning are relatively common and most were in the River Thames. Most drowning deaths occurred to boys and there was no social class difference. Two thirds of children drowned in water with unrestricted public access; swimming lessons for preschool children must, therefore, be a local priority.

Much current accident prevention education is directed towards home safety and while domestic accidents formed our smallest group, many were clearly preventable. Wilkinson ${ }^{6}$ found a noticeable reduction in death rates from burns and scalds between 1931-5 and 1968-72; this was most evident in relation to scalds and ignition of clothing. This reduction had been due in part to education of parents but also to legislative measures concerning fire proofing of fabrics. Learmonth ${ }^{7}$ showed that burns and scalds in Bradford were associated with overcrowding and Colver $e t a l^{8}$ suggested that accidents in some disadvantaged families result from practical and financial difficulties rather than parental ignorance or apathy. The paucity of domestic accidents we observed may simply reflect local affluence.

While a reduction in accidental ingestion of poisons has been observed since the introduction of child resistent drug packaging, ${ }^{9}$ we found no deaths from drug or poison ingestion, either before the 1976 legislation or afterwards.

The most important cause of non-natural death in childhood is road traffic accidents, most involving the child as pedestrian or cyclist. While the United Kingdom has the worst record in Europe in respect of pedestrian casualties, ${ }^{10}$ this is not true of fatal accidents to pedestrians, ${ }^{11}$ although there is no room for complacency. Our findings are similar to those of other studies with an excess of deaths in young boys and an excess in children of manual workers, although boys are no worse than girls at crossing roads $^{10}$ and children of all social classes play on the streets. ${ }^{12}{ }^{13}$ Scandinavian studies ${ }^{14} 15$ conclude that children are unreliable on the road until the age of 8 or 9 and cyclists are not really competent in traffic until the age of $13 .{ }^{17}$ We must continue to remind all 
road users, not just parents and children, about the child's vulnerability on the road. ${ }^{16}$

A new finding from this study is the clustering of accidents, particularly those resulting from spontaneous behaviour of the child around the time of their birthdays. Brown and Davidson ${ }^{17}$ found an association between childhood accidents and threatening life events. Here, we suggest that birthdays behave as life events, although from the child's point of view they would certainly not be considered threatening. Nevertheless the excitement evoked by anticipation or recollection of a birthday is obviously one that may distract the child from his usual careful behaviour. There were no sex or social class differences among those accidents clustered around the birthday. Only one death occurred on a birthday but this does not invalidate the association as school and parental work commitments are likely to influence the timing of social events.

Regional analysis of fatal accidents may indicate how local action might usefully reduce accidents to children, and focus public attention on the child's vulnerability in ways that national campaigns, by their impersonal nature, have failed to do.

This study was started while the late Dr John Baldwin was Director of the Oxford Record Linkage Study. We are grateful to the Acting Director, Dr Michael Goldacre for permission to continue and to Mrs Bettine Sutton for valuable clerical assistance. Dr Wendy Graham kindly helped supply the population data. Jean Golding is the holder of a Wellcome Trust Senior Lectureship.

\section{References}

1 Office of Population, Censuses and Surveys. OPCS Monitor DH2 84/2. London: Office of Population Censuses and Surveys, 1984.
${ }^{2}$ Baldwin JAB. The Oxford record linkage study as a medical information system. Proceedings of the Royal Society of Medicine 1972;65:237-9.

${ }^{3}$ Office of Population Censuses and Surveys. Classification of occupations. London: HMSO, 1970.

4 Keeling J, Golding J, Sutton B. Identification of cases of sudden infant death syndrome from death certificates. $J$ Epidemiol Community Health 1985; in press.

5 Sunderland R. Dying young in traffic. Arch Dis Child 1984;59:754-7.

6 Wilkinson AW. Some aspects of burns and scalds in children. In: Jackson RH, ed. Children, the environment and accidents. London: Pitman Medical, 1977;103-12.

${ }^{7}$ Learmonth A. Factors in child burn and scalds accidents in Bradford 1969-73. J Epidemiol Community Health 1979;33: 270-3.

${ }^{8}$ Colver AF, Hutchinson PJ, Judson EC. Promoting children's home safety. Br Med J 1982;285:1177-80.

${ }^{9}$.Forsyth JS, Hayman ME. Changing pattern of poisoning in children. Br Med J 1983;287:496.

10 Havard JDJ. Child pedestrian casualties as a public health problem. Med Sci Law 1974;14:168-79.

11 Avery JG, Avery PJ. Scandinavian and Dutch lessons in childhood road traffic accident prevention. $\mathrm{Br}$ Med $J$ 1982;285:621-6.

12 Russam K. The psychology of children in traffic. In: Jackson RH, ed. Children, the environment and accidents. London: Pitman Medical, 1977;49-65.

13 Adelstein AM, White GC. Causes of children's deaths analysed by social class (1959-63). In: Studies on medical and population studies no. 31. London: HMSO, 1976;24-40.

14 Sandels S. Children in traffic. London: Elek, 1975.

15 Bäckström K. In: Berfenstam R, et al, eds. Prevention of accidents in children. Uppsala: University Hospital, 1977.

16 Jackson RH. Accidents in childhood. Dev Med Child Neurol 1979;21:534-6.

17 Brown GW, Davidson S. Social class, psychiatric disorder of mother and accidents to children. Lancet 1978;i:378-80.

Correspondence to Dr J W Keeling, Department of Paediatric Pathology, John Radcliffe Maternity Hospital, Headington, Oxford OX3 9DU.

Received 7 February 1985 